\title{
ANTIRETROVIRAL THERAPY - CHANGES OF BASIC LABORATORY PARAMETERS IN HIV-INFECTED BULGARIAN PATIENTS
}

\author{
N. Yancheva, I. Elenkov, T. Tomov, D. Strashimirov and T. Tchervenyakova \\ Department for Patients with Acquired Immune Deficiency, Specialized Hospital for Active Treatment \\ of Infectious and Parasitic Diseases „Prof. Ivan Kirov" - Sofia
}

Summary. HIV-1 infection keeps on being a global problem because of its pandemic character and the impossibility for eradication. The combined antiretroviral therapy (ART) remains the only treatment which has proven its effectiveness for maintaining the life of HIV positive patients. Because of long term (life time) duration of this therapy, it is necessary to monitor patients for possible drug toxicity. The aim of our research is to evaluate the changes of basic laboratory examinations while conducting a long-term ART. We analyzed basic laboratory studies of 145 HIV-infected Bulgarian patients in the current research. The patients were separated into four groups according to their treatment regimen. They were on dispensary monitoring and were being treated in the Department for Patients with Acquired Immune Deficiency in the Specialized Hospital for Active Treatment of Infectious and Parasitic Diseases "Prof. Ivan Kirov" - Sofia. Our results showed that combined ART led to changes in blood count, alanin-aminotransferase (ALT), glucose and total cholesterol. Some of these changes are significant for some of the drugs administered. The current ART does not lead to severe toxicity and life-threatening conditions such as those which were observed in the first few years of ART introduction.

Key words: HIV, ART, combined antiretroviral therapy, laboratory parameters

\section{INTRODUCTION}

HIV-1 infection keeps on being a global problem because of its pandemic character and the impossibility for eradication. At the moment there is not a therapeutic model available for the eradication of HIV. The combined antiretroviral therapy (ART) remains the only treatment which has proven its effectiveness for maintaining the life of the HIV positive patients. Nowadays the HIV infection has turned into a chronic 
disease with significantly longer life expectancy of the patients, as long as they are on a suitable ART. The development of the ART marked one of the most dramatic inventions in the history of medicine. The objectives of the ART include reduction of deaths and morbidity caused by HIV as well as improvement of the quality of life, the recovery and the preservation of the patient's immune function and the replication control over the HIV virus [30]. These objectives are achieved when HIV-1 RNA level is suppressed to a lower value than $20-50$ copies $/ \mathrm{mL}$, which is determined by the limitations of current available diagnostic techniques.

There are five groups of antiretroviral medicaments according to their specific target enzyme in HIV-replication cycle - nucleoside inhibitors of the reverse transcriptase (NRTIs), non-nucleoside inhibitors of the reverse transcriptase (NNRTIs), protease inhibitors (PIs), integrase inhibitors (Ils) and entry inhibitors (including fusion inhibitors and CCR5 antagonists). When starting ART the recommended combinations are two nucleoside inhibitors plus one non-nucleoside inhibitor (2 NRTI + $1 \mathrm{NNRTI}$ ) or two nucleoside inhibitors plus one protease inhibitor (2 NRTI + 1 PI) or two nucleoside inhibitors plus one integrase inhibitor (2 $\mathrm{NRTI}+1 \mathrm{II})$.

Some studies showed that oxidative stress could be the main factor for the toxicity in the treatment with antiretroviral drugs [2, 4, 13, 23]. Damaged antioxidants and antioxidant enzymes in HIV-positive patients treated with ART were found. The toxic effects such as lipodystrophy, myopathy, cardiomyopathy, anemia, lactic acidosis, pancreatitis, and neuropathy can occur due to oxidative stress while receiving ART. Some studies found the oxidative stress as a result of highly active ART with development of the mitochondrial dysfunction [37, 40]. Other studies revealed that the combined ART itself led to increased oxidation of the proteins and an increased level of the already existing oxidative stress caused by HIVinfection [23].

\section{AIM OF THE STUDY}

The aim of our study is to evaluate the changes of some basic laboratory parameteres - blood count, blood glucose, cholesterol, alanine aminotransferase (ALT) and creatinine while receiving a long-term ART.

\section{MATERIAL AND METHODS}

We analyzed laboratory examinations of $145 \mathrm{HIV}$-infected Bulgarian patients in the current research. The patients were separated in four groups according to their treatment regimen. They were on dispensary monitoring and were being treated in the Department for Patients with Acquired Immune Deficiency in the Specialized Hospital for Active Treatment of Infectious and Parasitic Diseases "Prof. Ivan Kirov" - Sofia. The gender distribution of the patients is shown on figure 1. 


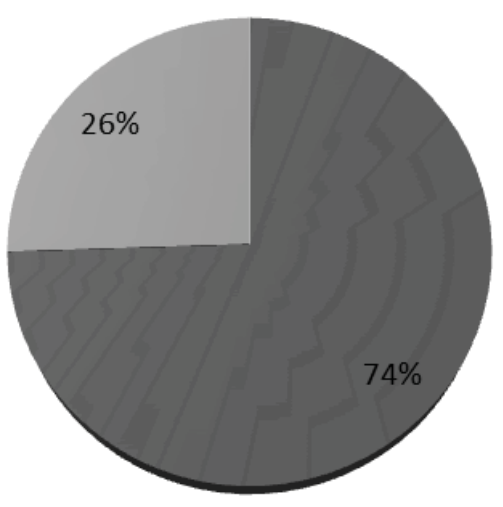

Fig. 1. The gender distribution of the examined HIV-infected patients

The average age of the tested subjects was $34.9 \pm 9.3$ years. The average age of men was $34.8 \pm 9.2$ years and that of the women was $35.2 \pm 9.5$.

Patients were monitored on an ambulatory basis. No complications requiring hospitalization were registered during the ongoing therapy. Most of the patients had ART with different continuance, but there are also untreated (naive) patients. Tests were routinely performed during the dispensary monitoring of HIV-infection in the Clinical laboratory of SHATIPD "Prof. Ivan Kirov". In order to study the influence of the ART by the measured laboratory parameters of the monitored patients, we divided them later into four groups: patients without treatment (naive), patients treated with Efavirenz (EFV), treated with Nevirapine (NVP) and treated with protease inhibitors. There were $35(24.1 \%)$ patients in the first group, in the second - $33(22.8 \%)$ patients, in the third $-8(5.5 \%)$ patients and in the fourth $-69(47.6 \%)$ patients. This distribution is shown in Fig. 2.

\section{naïve=35 —EFV=33 $\quad \mathrm{Pl}=69 \quad \mathrm{NVP}=8$}

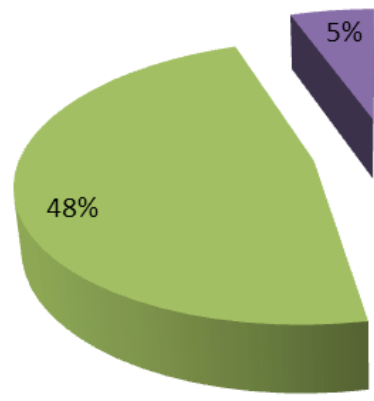

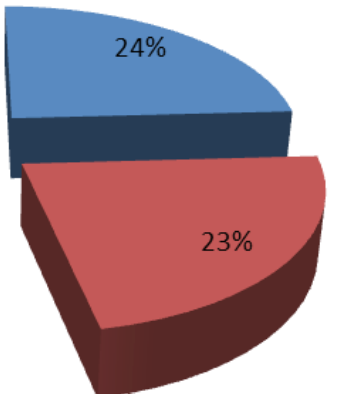

Fig. 2. Distribution of the examined patients (\%), divided into four groups according to their treatment regimen. Naïve - untreated, EFV on Efavirenz, NVP - on Nevirapine, $\mathrm{PI}$ - on Protease inhibitors 
We applied one way ANOVA in order to evaluate the difference in the parameters of the tested patients. To find the significant differences in the tested parameters in the four groups, we did a post hoc Duncan test.

\section{RESULTS AND DISCUSSION}

The medications EFV (Efavirenz) and NVP (Nevirapine) are non-nucleoside inhibitors. In order to give a better evaluation of a possible hepatotoxic effect they are placed in different groups. According to literature data [21, 22, 34, 46, 48, 53], more prominent hepatotoxicity is found in patients who are treated with NVP (nevirapine).

After analyzing the data from the blood count during ART we did not find any significant differences in the average values of the haemoglobin level. We found difference between the groups in their average values of the red blood cells (RBCs) (Table 1).

Table 1. Mean values, standard deviation, patients with lower values of red blood cells (RBCs) (number and \%), according to the ART regimen

\begin{tabular}{|c|c|c|c|}
\hline ART & $\begin{array}{l}\text { RBCs } \\
\text { Mean } \pm \mathrm{SD}\left(\times 10^{12} / l\right)\end{array}$ & $\begin{array}{l}\text { Patients with lower RBCs } \\
\mathrm{n}(\%)\end{array}$ & Significance, $p$ \\
\hline Naïve patients & $4.78 \pm 0.57$ & $1(2,9)$ & \multirow{4}{*}{$\begin{array}{l}\text { Naive/treated } \\
p=0.004238 \\
\text { EFV/NVP } \\
(p=0.003276)\end{array}$} \\
\hline Treated with EFV & $4.44 \pm 0.55$ & $3(19)$ & \\
\hline Treated with NVP & $3.53 \pm 0.79$ & $6(37.5)$ & \\
\hline Treated with PI & $4.18 \pm 0.64$ & 10 (14.5) & \\
\hline
\end{tabular}

The average count of the erythrocytes in the untreated patients was higher than in those patients who were treated with NVP and protease inhibitors $(p=0.004238)$. According to these results we can assume that the ART thoroughly leads to a reduction in the RBCs in the treated patients compared to the non-treated.

The common feature between the treatment regimen of the treated patients is the combination of two NRTIs. The difference between the treated patients is in the third component of the therapy. According to the literature among those who were treated with ART mainly NRTIs have suppressive effects on patients' bone marrow [28].

In addition to these results, in $2.9 \%$ of the untreated patients, the level of the RBCs is below the lower reference interval. In the other groups $-37.5 \%$ of the patients treated with NVP, $19 \%$ of the patients treated with EFV and $14.5 \%$ of the patients treated with protease inhibitors had lower RBCs level than the reference interval

Anemia is a common manifestation of HIV-infection and it is an independent predictor of higher morbidity and death rate $[7,50]$. In most cases anemia can be 
cured after at least 6 months of treatment, while the patient is still on ART. In other cases anemia can persist despite ART. According to Berhane et al., 2004, and Redig et al., 2013, anemia is often associated with aging and it is also a result of chronic inflammation during the HIV infection.

We did not find any relation between the age of our patients and their hemoglobin and erythrocytes levels. Our analyses also showed that the average levels of erythrocytes of the patients treated with EFV are higher than the average levels of those treated with NVP $(p=0.003276)$.

While evaluating the impact of ART upon the values of the leukocyte counts we found that the average count of leukocytes of the untreated men and those treated with protease inhibitors, are significantly higher than those treated with non-nucleoside inhibitors ( $p=0.042414, p=0.0301124$, respectively).

The untreated patients have a preserved bone marrow function, evaluated by the normal levels of leukocytes and CD4-positive lymphocytes, thus these patients had not started ART. When comparing the protease and non-nucleoside inhibitors, according to literature data [30] it appears that the overall numbers of the leukocytes and CD4-positive cells are higher when treated with protease inhibitors compared to non-nucleoside inhibitors.

Statistical analysis revealed significant differences in the average values of the platelet count, depending on ART regimen - lower platelet count in $6.6 \%$ of the EFV treated patients, in $5.4 \%$ of the naïve patients, in $1.4 \%$ of the patients treated with protease inhibitors and in $12.5 \%$ of the NVP treated ones (Table 2). On the other hand $1.4 \%$ of the patients treated with protease inhibitors and $12.5 \%$ of those treated with NVP had higher than the upper reference interval platelet levels. The average platelet levels of the patients treated with Nevirapin were higher than the average platelet levels of the untreated patients $(p=0.032396)$.

This time we compared the treated and untreated patients. The treated patients have a lower viral load than the untreated.

According to a cohort study [30] the number of platelets has an inversely proportional link to the viral load of HIV. The number of platelets increases when the viral load decreases. That confirms our results - higher platelet levels are observed in treated patients, compared to the untreated ones.

Another result of our analysis is that the average value of platelets of the treated with protease inhibitors group is higher than that of the treated with EFV patients $(p=0.039528)$.

This could be interpreted as an effect of a better immunological and virological response to therapy.

The average values of the platelets and the standard deviations of the different groups according to their therapy are shown in Table 2. 
Table 2. The average values, standard deviation, number and $\%$ patients with abnormal values of platelets $(\mathrm{PIt})$

\begin{tabular}{|c|c|c|c|c|c|}
\hline \multirow{3}{*}{$\begin{array}{l}\text { ART regimen } \\
\text { Naive patients }\end{array}$} & \multirow{3}{*}{\begin{tabular}{|l} 
PIt mean, $x 10^{9} / 1$ \\
224.14 \\
\end{tabular}} & \multirow{3}{*}{$\begin{array}{l}\text { SD } \\
64.29\end{array}$} & \multicolumn{2}{|c|}{ Abnormal values of PIt } & \multirow{3}{*}{$\begin{array}{l}p \\
\text { NVP/naive }\end{array}$} \\
\hline & & & & $\%$ & \\
\hline & & & 2 & 5,4 & \\
\hline Treated with EFV patients & 226.45 & 85.32 & 2 & 6,6 & $p=0.032396$ \\
\hline Treated with NVP patients & 282.88 & 117.21 & 1 & 12,5 & \multirow{2}{*}{$\begin{array}{l}\mathrm{PI} / \mathrm{EFV} \\
\mathrm{p}=0.039528\end{array}$} \\
\hline Treated with PI patients & 253.77 & 85.32 & 1 & 1,4 & \\
\hline
\end{tabular}

After analyzing the biochemical blood parameters we found significant differences between the average values of ALT and cholesterol, depending on the treatment regimen. The average value of ALT in patients treated with Nevirapin is significantly higher compared to those treated with Pls $(p=0.049865)$. The average values, standard deviations of the ALT mean level and the number and percentage of the patients with higher levels are shown in Table 3.

Table 3. Average value, standard deviation and patients with elevated ALT (number and \%) according to the applied therapy

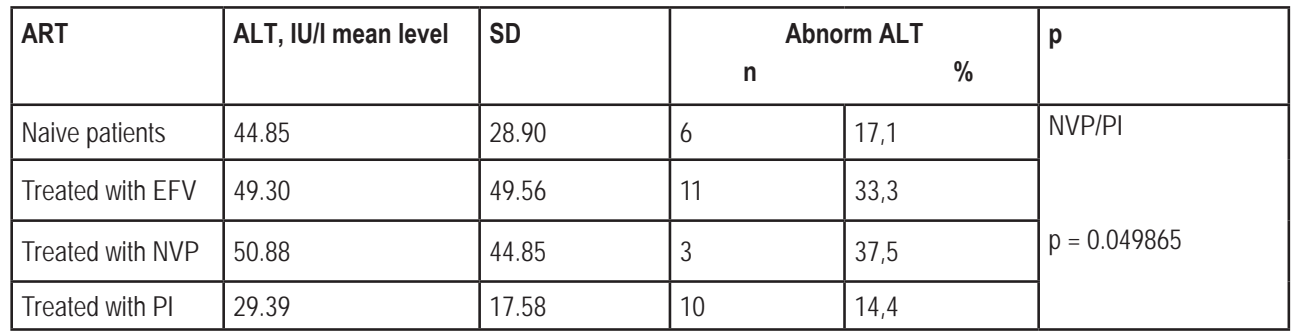

Higher than the reference interval levels of ALT were found in $37.5 \%$ of the patients treated with Nevirapin.

According to data from Sanne, the female gender is one of the risk factors for hepatotoxicity caused by Nevirapine [52].

Our results showed significant difference between the men treated with $\mathrm{Ne}$ virapin compared to the untreated and compared to those who were treated with protease inhibitors. The average level of ALT in men who were treated with Nevirapin is significantly higher than the average level in the untreated and those who were treated with protease inhibitors ( $p=0.009804, p=0.005635$, respectively).

Our results showed similarity with other researchers who stated that the treatment with Nevirapin is characterized by elevated liver enzymes [34, 46, 48, 56]. Other authors did not detect such effects of the Nevirapin [49]. The analyses of Torti 
and colleagues showed a higher risk of Nevirapin-induced toxicity in patients who are co-infected with hepatitis C [56].

In our research, in the group of those treated with Nevirapin, $25 \%$ of the patients are co-infected with hepatitis C.

From the patients who are treated with EFV, 33.3\% had increased values of ALT and $15 \%(n=5)$ had the co-infection with hepatitis. In the group of the untreated patients $17.1 \%$ had increased values of ALT and $25.9 \%(n=9)$ of them were coinfected with hepatitis. Ten of the patients $(14.4 \%)$ treated with protease inhibitors had ALT level above the normal reference range, and $18.6 \%(n=13)$ of them were co-infected with hepatitis.

In Table 4 there are shown the average cholesterol levels of the tested patients depending on their therapy regimen and the number and percentage of the patients with higher cholesterol levels. The average amount of the cholesterol in the group of those treated with EFV is significantly higher than the average amount of the group with the untreated patients $(p=0.04986)$.

In this case the result of higher cholesterol could be considered as caused by the ART.

According to most studies protease inhibitors are the antiretroviral medicaments which mainly lead to deviations in the lipid profile [29, 44, 45, 54]. Those of our patients who were treated with non-nucleoside inhibitors showed dyslipidemia in higher percentage. In the group of patients with NVP, 37.5\% had cholesterol levels higher than the normal range. From the treated with EFV patients $33.3 \%$ had increased cholesterol levels, $21.7 \%$ of those treated with protease inhibitors and $5.4 \%$ of the untreated patients had increased cholesterol levels.

Table 5 shows the average value of blood glucose and the number and percentages of the patients with increased blood glucose level. We found that $37.5 \%$ of the patients treated with Nevirapin and $36.9 \%$ of the patients on Efavirenz had increased levels of blood glucose, while in the group of those treated with protease inhibitors $24.6 \%$ had increased levels of blood glucose.

Protease inhibitors are considered to be the main antiretroviral medicament group which leads to glucose intolerance [29, 54]. No significant difference between the groups was found in our analyses, but we observed a higher percentage of patients treated with non-nucleoside inhibitors with higher blood glucose levels.

Table 4. Average values, standard deviations and patients (number and \%) with elevated cholesterol levels according to ART.

\begin{tabular}{|c|c|c|c|c|c|}
\hline ART & $\begin{array}{l}\text { Cholesterol, mmol/l } \\
\text { Mean }\end{array}$ & SD & \multicolumn{2}{|c|}{\begin{tabular}{|c|} 
Patients with elevated cholesterol \\
$\mathrm{n}$
\end{tabular}} & $p$ \\
\hline Naïve patients & 4.46 & 1.11 & 2 & 5,4 & \multirow{4}{*}{$\begin{array}{l}\text { EFV/naive } \\
p=0.04986\end{array}$} \\
\hline Treated with EFV & 5.88 & 4.85 & 11 & 33,3 & \\
\hline Treated with NVP & 5.51 & 2.31 & 3 & 37,5 & \\
\hline Treated with PI & 5.06 & 1.61 & 15 & 21,7 & \\
\hline
\end{tabular}


Table 5. Average values, standard deviations and patients (number and \%) with elevated glucose levels according to the ART

\begin{tabular}{|c|c|c|c|c|c|}
\hline ART & $\begin{array}{l}\text { Glucose, } \mathrm{mmol} / \mathrm{l} \\
\text { Mean }\end{array}$ & SD & \multicolumn{2}{|c|}{$\begin{array}{c}\text { Patients with elevated glucose } \\
\mathrm{n}\end{array}$} & $p$ \\
\hline Naïve patients & 5.86 & 0.78 & 2 & 5,4 & \multirow{4}{*}{$p=0.06678$} \\
\hline Treated with EFV & 5.66 & 0.86 & 12 & 36,9 & \\
\hline Treated with NVP & 6.20 & 0.83 & 3 & 37,5 & \\
\hline Treated with PI & 5.76 & 0.97 & 17 & 24,6 & \\
\hline
\end{tabular}

We did not discover significant differences between the average levels of creatinine in the groups on different treatment regimen.

\section{CONCLUSION}

The combined ART is the only effective way to support life among the HIVpositive patients. The current antiretroviral drugs do not lead to the same severe side effects and life-threatening conditions observed in the first few years after ART introduction. However, long-term therapy requires strict monitoring not only for its therapeutic effect but also for control of the basic laboratory parameters levels which should be corrected instantly.

\section{REFERENCES}

1. Еленков, И., Н. Янчева, Т. Червенякова и сътр. Антиретровирусна терапия - историческо развитие и групи антиретровирусни медикаменти. - Български медицински журнал, 4, 2010, № 29, 7-21.

2. Adikwu, E., N. Brambaifa, Deo Oputiri and Oru-Bo Precious Geoffrey. Antiretroviral toxicity and oxidative stress. - Am. J. Pharmacol. Toxicol. 8 (4): 187-196, 2013.

3. Arnaudo, E., M. Dalakas, S. Shanske et al. Depletion of muscle mitochondrial DNA in AIDS patients with zidovudine-induced myopathy. - Lancet, 1991, 337:508-510.

4. Atiba, A. S., D.P. Oparinde, A. K. Jimoh et al. Oxidative stress and serum selenium in HIVpatients on different antiretroviral regimen. - Greener J. Med. Sci., 2012, 2: 163-167.

5. Becher, F., A. Pruvost, D. Schlemmer et al. Significant levels of intracellular stavudine triphosphateare found in HIV-infected zidovudine-treated patients. - AIDS 2003, 17:555-61.

6. Ben-Romano, R., A. Rudich, S. Etzion et al. Nelfinavir induces adipocyte insulin resistance through the induction of oxidative stress: Differential protective effect ofantioxidant agents. - Antivir. Ther. 2006, 11: 1051-1060.

7. Berhane, K, R. Karim, M. Cohen, L. Masri-Lavine et al. Impact of highly active antiretroviral therapy on anemia and relationship between anemia and survival in a large cohort of HIV-infected women: Women's Interagency HIV Study. - J Acquir Immune Defic Syndr. 2004;37(2):1245.

8. Bonora, S., M. Boffito, A. D'Avolio et al. Detection of stavudine concentrations in plasma of HIVinfected patients taking zidovudine. - AIDS 2004, 18:577-8. 
9. Brinkman, K., J. Smeitink, J. Romijn, P. Reiss. Mitochondrial toxicity induced by nucleoside-analoguereverse-transcriptase inhibitors is a key factor in the pathogenesis of antiretroviral-therapyrelated lipodystrophy. - Lancet 1999, 354:1112-5.

10. Cameron, D., M. Heath-Chiozzi, S. Danner et al. Randomised placebo-controlled trial of ritonavir in advanced HIV-1 disease. - Lancet 1998, 351:543-9.

11. Carr, A., J. Miller, M. Law, D. Cooper. A syndrome of lipoatrophy, lactic acidaemia and liver dysfunction associated with HIV nucleoside analogue therapy: contribution to protease inhibitor-related lipodystrophy syndrome. - AIDS 2000, 14:F25-F32.

12. Carr, A., D. Cooper. Adverse effects of antiretroviral therapy. - Lancet 2001; 356:1423-30.

13. Chndra, S., D. Mondal and K.C. Agrawal. HIV-1protease inhibitor induced oxidative stress suppresses glucose stimulated insulin release:Protection with thymoquinone, experim. - Biol. Med. 2009, 234: 442-453.

14. Chun, T. W. et al. Rebound of plasma viremia following cessation of antiretroviral therapy despite profoundly low levels of HIV reservoir: implications for eradication. - AIDS 24(18): 2803-8. November 27, 2010.

15. Cohen, C., J. Andrade-Villanueva, B. Clotet et al. Rilpivirine versus efavirenz with two background nucleoside or NRTIs in treatment-naïve adults infected with HIV-1(THRIVE): a phase 3, randomized non-inferiority trial. - Lancet 2011, 378(9787):229-37.

16. Concorde: MRC/ANRS randomised double-blind controlled trial of immediate and deferred zidovudine in symptom-free HIV infection. - Lancet 1994, 343:871-81.

17. Cossarizza, A. and G. Moyle. Antiretroviral nucleoside and nucleotide analogues and mitochondria. - AIDS 2004, 18: 137-151.

18. Côté, H., B. Yip, J. Asselin et al. Mitochondrial:nuclear DNA ratios in peripheral blood cells from human immunodeficiency virus (HIV)-infected patients who received selected HIV antiretroviral drug regimens. - J Infect Dis 2003, 187:1972-6.

19. Côté, H., A. Magil, M. Harrig et al. Exploring mitochondrial nephrotoxicity as a potential mechanism of kidney dysfunction among HIV-infected patients on highly active antiretroviral therapy. - Antivir Ther 2006, 11:79-86.

20. Elias, A. and N. Brambaifa, 2013. Concentration-effect, incidence and mechanism of nevirapine hepatotoxicity. - Am. J. Pharmacol. Toxicol., 8: 20-30.

21. Elias, A., O. Deo, O. Geoffrey and D. Enimeya. Nevirapine hepatotoxicity: Implications of risk factors. - Am. J. Pharm. Toxicol. 8: 2013, 51-63.

22. Elias, A., N. Brambaifa et al. Antiretroviral toxicity and oxidative stress. - Am. J. Pharmacol. Toxicol. 8 (4): 187-196, 2013.

23. Eron, J. HIV-1 protease inhibitors. - Clin Infect Dis 2000, 30 Suppl 2: S160-170.

24. Fellay, J., K. Boubaker et al. Prevalence of adverse events associated with potent antiretroviral treatment:Swiss HIV Cohort Study, - Lancet 2001; 358(9290); 1323-1327.

25. Galli, M., A. Ridolfo, F. Adorni et al. Body habitus changes and metabolic alterations in protease inhibitor-naive HIV-1-infected patients treated with two nucleoside reverse transcriptase inhibitors. - JAIDS 2002, 29(1):21-31.

26. Glesby, D. R. Overview of mitochondrial toxicity of nucleoside reverse transcriptase inhibitors. IAS-USA, 10, 2002, № 1.

27. Hassan, A., A. A. Babadoko, A. I. Mamman and S. Ahmed. Zidovudine induced pure red cell aplasia: A case report. - Niger J. Med., 2009, 18: 332-333.

28. Hill, A., W. Sawyer and B. Gazzard. Effects of first-line use of nucleoside analogues: Efavirenz and ritonavir-boosted protease inhibitors on lipid levels. - HIV Clin. Trials. 2009, 10: 1-12.

29. Hoffman, C., J. Rockstroh. HIV 2012/2013. Hamburg. - Medizin Fokus Verlag, 2012. 
30. Hughes, P., E. Cretton-Scott, A. Teague and T. M. Wensel. Protease inhibitors for patients with HIV-1 infection: A comparative overview. P T., 2011, 36: 332-345.

31. Izzedine, H., J. Hulot, D. Vittecoq et al. Long-term renal safety of tenofovir disoproxil fumarate in antiretroviral-naive HIV-1-infected patients. Data from a double-blind randomized active-controlled multicentre study. - Nephrol Dial Transplant 2005, 20:743-6.

32. James, C., P. Lee and M. Sweet. Rilpivirine: A second-generation nonnucleoside reverse transcriptase inhibitor. - Am. J. Health-Syst. Pharm., 2012, 69: 857-861.

33. Jena, A., R. Sachdeva, A. Sharma and A. Wanchu. Adverse drug reactions to nonnucleoside reverse transcriptase inhibitor-based antiretroviral regimen: A 24-week prospective Study. J. - Int. Assoc. Providers of AIDS Care, 2009, 8: 318-322.

34. Lewis, W. Mitochondrial dysfunction and nucleoside reverse transcriptase inhibitor therapy: Experimental clarifications and persistent clinical questions. - Anti. Res. 2003, 58: 189-197.

35. Mallon, P., P. Unemori, R. Sedwell et al. In vivo, nucleoside reverse-transcriptase inhibitors alter expression of both mitochondrial and lipid metabolism genes in the absence of depletion of mitochondrial DNA. - J Infect Dis., 191, 2005, № 10, 1686-1696.

36. Mandas, A., E. Lorio, M. Congiu, C. Balestrieri and A. Mereu et al. Oxidative imbalance in HIV- 1 infected patients treated with antiretroviraltherapy. - J. Biomed. Biotechnol., 2009, 18: 67-79.

37. Manfredi, R., L. Calza. Nevirapine versus efavirenz in 742 patients: no link of liver toxicity with female sex, and a baseline CD4 cell count greater than 250 cells/microl. - AIDS, 20, 2006, № 17, 2233-2236.

38. Martinez, E., J. Arnaiz, D. Podzamczer et al. Substitution of nevirapine, efavirenz or abacavir for protease inhibitors in patients with HIV infection. - N Eng J Med 2003; 349:1036-1046.

39. Masia, M., S. Padilla, E. Bernal, M. V. Almenar and J. Molina et al. Influence of antiretroviral therapy on oxidative stress and cardiovascular risk:A prospective cross-sectional study in HIV-infected patients. - Clin. Therap., 2007, 29: 448-455.

40. Mbuagbaw, L., J. Irlam, A. Spaulding et al. Efavirenz or nevirapine in three-drug combination therapy with two nucleoside-reverse transcriptase inhibitors for initial therapy of HIV infection in antiretroviral - naïve individuals. - Cochrane Database Syst Rev 2010,12:CD004246.

41. Milazzo, L., B. Menzaghi, I. Caramma, M. Nasi and O. Sangaletti et al. Effect of antioxidants on mitochondrial function in HIV-1-related lipoatrophy: A pilot study. - AIDS 2010, 26: 1207-1214.

42. Moyle, G., M. Sadler. Peripheral neuropathy with nucleoside antiretrovirals: risk factors, incidence and management. - Drug Safety 1998, 19:481-94.

43. Nolan, D. Metabolic complications associated with HIV protease inhibitor therapy. - Drugs 2003, 63:2555-74.

44. Noor, M. The role of protease inhibitors in the pathogenesis of HIV-associated insulin resistance: Cellular mechanisms and clinical implications. - Curr. HIVIAIDS Rep., 2007, 4: 126-134.

45. Nunez, M. Clinical syndromes and consequences of antiretroviral-related hepatotoxicity. - Hepatology 2010, 52, № 3: 1143-1155.

46. Ouyang, D., D. Shapiro, M. Lu et al. Increased risk of hepatotoxicity in HIV - infected pregnant women receiving antiretroviral therapy independent of nevirapine exposure. - AIDS 2009.23:2425-2430.

47. Peters, P., J. Striner, M. McConnell et al. Nevirapine-associated hepatotoxicity was not predicted by CD 4 count $>250$ cells/ml, among women in Zambia, Thailand and Kenya. - HIV Med 2010;11:650-60.

48. Podzamczer, D., E. Ferrer, E. Consiglio et al. A randomized clinical trial comparing nelfinavir or nevirapine associated to zidovudine/lamivudine in HIV-infected naive patients (the Combine Study). - Antivir.Ther. 2002, 7:81-90.

49. Redig, A., N. Berliner. Pathogenesis and clinical implications of HIV-related anemia in 2013. - Hematology Am Soc Hematol Educ Program. 2013;2013:377-81. 
50. Regidor, D., R. Detels, E. Breen, D. Widney et al. Effect of highly active antiretroviral therapy on biomarkers of B-lymphocyte activation and inflammation. - AIDS 2011:303-314.

51. Rivero, A. and A. Jose. Liver toxicity induced by non-nucleosidereverse transcriptase inhibitors. - J. Antimicrob. Chemother. 2009, 59: 342-346.

52. Sanne, I., H. Mommeja-Marin, J. Hinkle et al. Severe hepatotoxicity associated with nevirapine use in HIV-infected subjects. - J Infect Dis 2005;191:825-9.

53. Storfer, S., J. Leith, P. Piliero, D. Hall. Analysis of hepatic events within the 2NN study: controlling for ethnicity and CD4+ count at initiation of nevirapine therapy. - Abstract PE9.6/2. 10th EACS 2005. Dublin.

54. Tebas, P. Insulin resistance and diabetes mellitus associated with antiretroviral use in HIV-infected patients: Pathogenesis, prevention and treatment options. - J. Acquir. Immun. Defic. Syndr. 2008, 49: S86-92.

55. Terry, L., E. Sprinz, R. Stein, N. Medeiros and J. Oliveira et al.Exercise training in HIV-1- infected individuals with dyslipidemia and lipodystrophy. - Med. Sci. Sports. Exerc.2006, 38: 411-417.

56. Torti C, S. Costarelli, A. De Silvestri et al. Analysis of severe hepatic events associated with nevirapine-containing regimens: CD4+ Th cell count and gender in hepatitis $\mathrm{C}$ seropositive and seronegative patients. - Drug Saf 2007, 30:1161-9.

57. Vander Valk, M., Reiss P. Lipid profiles associated with antiretroviral drug choices. - Curr Opin Infect Dis2003, 16: 19-23.

58. Walker, U., B. Setzer, N. Venhoff. Increased long-term mitochondrial toxicity in combinations of nucleoside analogue reverse transcriptase inhibitors. - AIDS 2002, 16(16):2165-73.

\section{Corresponding author:}

Dr Nina Stojanova Jancheva, MD

Department of Infectious Diseases, Parasitology and Tropical Medicine,

Sofia Medical University

Ward for Patients with Acquired Immunodeficiency

Hospital "Prof. Ivan Kirov"

17 "Academic Ivan Geshov" Blvd. - Sofia

e-mail: dr.yancheva@abv.bg 